\title{
Selenium species in selenium-enriched malt
}

\author{
Diomid Revenco ${ }^{1}$, Marie Vomáčková1, Lukáš Jelínek², Oto Mestek ${ }^{3}$, Richard Koplík ${ }^{1}$ \\ Department of Food Analysis and Nutrition \\ 2 Department of Biotechnology \\ 3 Department of Analytical Chemistry, University of Chemistry \\ and Technology, Prague, Technická 5, 16628 Prague 6 \\ *Corresponding author: diomid1.revenco@vscht.cz
}

\begin{abstract}
Selenium-enriched malts were prepared by an application of sodium selenite solution to steeped barley grain and following germination and kilning. The changes of selenium valency and the biotransformation of inorganic selenium were investigated by selenium speciation analysis in enzyme-hydrolysed malt samples using liquid chromatography-inductively coupled plasma mass spectrometry. Both inorganic compounds (selenate, selenite) and Se-containing amino acids (selenocystine, Se-methyl-selenocysteine, selenomethionine) were found in green and kilned barley malt.
\end{abstract}

Key words: selenium, selenium species, malt

\section{Introduction}

Selenium is an essential element, which plays a number of important roles in the human body. It influences the synthesis of thyroidal hormones, the regulation of antioxidative processes and the production of prostaglandins, supporting growth and fertility (Velíšek, 2014). Due to the antioxidant properties of selenium containing amino acids and selenoproteins, it is assumed that bioactive selenium species have anticancerogenic effects (Irons et al. 2006; Roman et al. 2013)

Due to similar physicochemical properties, selenium can replace sulfur in common biomolecules such as amino acids. As a result, selenium-containing amino acids (e.g. selenocysteine, selenomethionine, and Se-methyl selenocysteine - see Figure 1), selenopeptides and selenoproteins appear in tissues of plants or animals, which reflect the exposure of an organism to selenium. For humans, the most important selenoproteins are enzymes glutathione peroxidase and triiodothyronine deiodase.

The main source of selenium intake for people is food. Selenium content in food reflects the occurrence of selenium in the environment. In crops and food of plant origin, selenium accumulation is roughly proportional to the selenium content in the soil. The absorption of se- lenium by plants depends on its concentration and the chemical forms present in the soil (Broadley et al., 2010). Selenium content in animal products interrelates with the levels of selenium contained in the feed the animals consumed.

Selenium is both essential and toxic and the range of concentrations within which it is beneficial is relatively narrow (EFSA, 2014). The recommended daily intake of selenium is $55 \mu \mathrm{g}$ for women and $70 \mu \mathrm{g}$ for men (Navarro-Alarcon et al., 2008; EFSA, 2014). In Europe, the highest tolerable daily intake dose of selenium was set at $300 \mu \mathrm{g}$ (Navarro-Alarcon et al., 2008; Scientific Committee on Food, 2000). Most plants do not have the ability to accumulate high levels of selenium (the levels rarely exceed $100 \mu \mathrm{g} \mathrm{g}^{-1}$ of dry matter)(Navarro-Alarcon et al., 2008).

Selenium deficiency is dangerous, especially when accompanied by concomitant vitamin E deficiency, which also acts as a protective factor against oxidative stress. One of the consequences of selenium deficiency is Keshan disease (Li et al., 1985).

Czech Republic belongs to the countries with a low content of selenium in soil. Therefore, the selenium con- 
Figure 1 Structures of L-selenocysteine, L-selenomethionine and L-Se-methyl-selenocysteine<smiles>[CH]C[C@H](N)C(=O)O</smiles><smiles>C[CH-]CC[C@H](N)C(=O)O</smiles><smiles>C[CH]C[C@H](N)C(=O)O</smiles>

centrations in crops cultivated here are mostly very low $\left(<0.05 \mathrm{mg} \mathrm{kg}^{-1}\right)$. With the exception of the cases of feed supplementation with selenium, the selenium content in animal products remains also quite low (Ludvíková et al., 2005; Stř́tecká et al., 2009; Kvičala et al., 2008). This situation could be improved in several ways: the fortification of fertilisers with an inorganic selenium compound (similar to the Finnish model from 1980s), the foliar application of inorganic selenium to grown plant crops, or the supplementation of feeds intended for farm animals with selenium in a suitable chemical form (Eurola et al., 1989; Bennett et al., 2010; Bañuelos et al., 2000). However, in order to achieve the best bioavailability of selenium, it should be applied in the form of organic species produced synthetically or created via metabolic transformation from inorganic species to organic ones during the technological process of production. A viable option for improving selenium intake in the Czech Republic could be the application of selenite or selenate during beer production, since the beer consumption per capita in the Czech Republic is the highest in Europe (The Brewers of Europe, 2018).

Knowledge of the total concentration of an element in foods is not enough for evaluating its actual effects. Therefore, it is mandatory to investigate the binding forms of the element present in foods, also called the element species (Templeton et al., 2000). The determination of element species in biological materials is most often achieved by a combination of two techniques of analysis: chromatography and atomic spectrometry. A remarkably powerful combination for this purpose is liquid chromatography hyphenated with inductively coupled plasma mass spectrometry (ICP-MS) (Szpunar, 2000). The analysis of selenium species was investigated by many researchers (e.g. Muñoz Olivas et al., 1994; Dauchy et al., 1994; Pyrzyńska, 1996; Uden, 2002; Dumont et al., 2006; B’Hymer et al., 2006; Pedrero et al., 2009; Pyrzyńska, 2009).

The hypothesis of the present work was that within the process of barley malting an inorganic compound of selenium is partially bio-transformed into organic selenium species as a result of the high metabolic activity of the germinating seeds. In this work, we have tested a sodium selenite application to the barley grains, in order to prove the transformation of inorganic selenium into organic species during the malting process, which is the condition that must be fulfilled before performing further work aimed at the production of selenium-enriched beer. To analyse total selenium content and selenium species, we applied the analytical technique of inductively coupled plasma mass spectrometry (ICP-MS) and the hyphenated technique of liquid chromatography coupled with ICP-MS

\section{Materials and methods}

\subsection{Preparation of malt samples}

Four malt samples were prepared: two control malts (green malt and kilned malt) and two Se-enriched malts (also green malt and kilned malt). The preparation of enriched malts included the addition of sodium selenite solution, while for the control samples the sodium selenite solution was omitted.

Grains of spring brewing barley were used as the basic raw material. The preparation of malts took place in a stainless steel micromaltery and included three steeping steps at $10{ }^{\circ} \mathrm{C}$ (of $8 \mathrm{~h}, 8 \mathrm{~h}$ and $3 \mathrm{~h}$ duration, respectively) interrupted by three aeration periods lasting $10 \mathrm{~h}$, $10 \mathrm{~h}$ and $3 \mathrm{~h}$, respectively. Then the portion intended for the preparation of Se-enriched malt (corresponding to ca $1 \mathrm{~kg}$ of grain) was disparted and spread over a support in a thin layer. An aqueous solution containing $200 \mathrm{mg}$ of $\mathrm{Na}_{2} \mathrm{SeO}_{3} \cdot 5 \mathrm{H}_{2} \mathrm{O}$ in the total volume of $8 \mathrm{ml}$ was then applied as an aerosol on the spread material using a small glass laboratory sprayer. Thereafter, the material was placed back into the micromaltery. This was followed by the grain germination for $48 \mathrm{~h}$ at $15^{\circ} \mathrm{C}$ with an over-turning period of $12 \mathrm{~h}$. At this stage, the samples $(50 \mathrm{~g})$ of green malt (both the Se-enriched and the control one) were taken from the corresponding batches, immediately frozen and stored in the freezer until the analysis. The remainder of the green malts (both Se-enriched and the control) was kilned according to the following temperature regime: $6 \mathrm{~h}$ of heating at $45^{\circ} \mathrm{C}, 6 \mathrm{~h}$ of heating at $50^{\circ} \mathrm{C}$, $10 \mathrm{~h}$ of gradual heating from 50 to $82^{\circ} \mathrm{C}$ and maintaining the temperature of $82^{\circ} \mathrm{C}$ for $2 \mathrm{~h}$. 


\subsection{Determination of total content and soluble content of selenium}

In order to determine the total content of selenium in malt samples or the total soluble part of selenium released by hydrolysis, the decomposition of corresponding samples was used as a sample preparation step. Sample portions of $500 \mathrm{mg}$ of malt or of $5 \mathrm{ml}$ of the supernatant resulting from malt hydrolysis (see chapter 2.3) were used for the decomposition. A dose of $3 \mathrm{ml}$ of $\mathrm{HNO}_{3}$ was used as the reagent. The decomposition was performed in DAK100 PTFE vessels of the microwave unit Speedwave 4 (Berghof, Königsee, Germany) and took 24 min of heating (at a maximum temperature of $230^{\circ} \mathrm{C}$ ) followed by cooling period of $50 \mathrm{~min}$. The resulting solutions were transferred into $50 \mathrm{ml}$ plastic calibrated flasks, spiked with an internal standard and filled up to the mark with distilled deionized water (DDW). Final concentration of the Ge internal standard was $40 \mu \mathrm{g} \mathrm{l}^{-1}$. The content of selenium was determined by ICP-MS working in the dynamic reaction cell mode with methane as a reaction gas using ELAN DRC-e ICP-MS instrument (Perkin-Elmer, Norwalk, CT, USA) equipped with a peristaltic pump, a glass concentric nebulizer and a glass cyclonic mist chamber with cooling capability. An external calibration technique was used for selenium quantification. Operating parameters of ICP-MS are shown in Table 1.

\subsection{Sample preparation for selenium speciation}

An enzymatic hydrolysis was used for sample preparation before LC-ICP-MS analysis. Before this step, the green malt sample was crushed in a porcelain mortar, while the kilned malt sample was pulverised in the laboratory mill (Waring 8010, USA). Then the sample portions of $200 \mathrm{mg}$ of malt were weighed into polypropylene screw-capped centrifuge tubes (30 ml, Sigma Laborzentrifugen, Germany); 25 mg of protease XIV from Streptomyces griseus (Sigma Aldrich, Germany) and $25 \mathrm{ml}$ of buffer solution (0.02 $\mathrm{moll}^{-1}$ Tris-HCl, $\mathrm{pH}=7.5$ ) were added into each tube, the tubes were closed and the samples were incubated in a laboratory thermostat (Binder ED 115, Germany) on a shaker (CAT S20, Germany) working at the frequency of $900 \mathrm{~min}^{-1}$ at $37^{\circ} \mathrm{C}$ for 22 hours. The samples were centrifuged $\left(15^{\circ} \mathrm{C}, 20.000 \mathrm{~g}, 20 \mathrm{~min}\right)$ and the resulting supernatants were used for further analyses (determination of total solubilised selenium and determination of selenium species). Prior to speciation analysis, the samples were diluted 10 times with the mobile phase.

\subsection{LC-ICP-MS analysis}

A coupling of reversed phase ion-paired chromatography and ICP-MS was used to determine the selenium species (Balán et al., 2014; Zheng et al., 2000). The chromatographic apparatus consisted of a high-pressure pump
Series 200 (Perkin-Elmer, USA), a Rheodyne 9010 injector (Index Health \& Science, Oak Harbor, WA, USA) with a $20 \mu$ l PEEK sample loop, a guard column Purospher RP18e $4 \times 4 m m \times 5 \mu \mathrm{m}$ and a Purosphere RP18e $150 \times$ 4,6 $\mathrm{mm} \times 3 \mu \mathrm{m}$ column (Merck, Darmstadt, Germany). The parts were connected by PEEK or PTFE capillaries. The outlet from the column was directly connected with the nebulizer of the ICP-MS instrument. Isocratic elution was used and the mobile phase contained $5 \mathrm{mmol} \mathrm{l}^{-1}$ sodium 1-butanesulfonate, $4 \mathrm{mmol}^{-1}$ malonic acid, $16 \mathrm{mmol}$ $\mathrm{l}^{-1}$ tetramethylammonium hydroxide, $1 \%(\mathrm{v} / \mathrm{v})$ methanol and added internal standard of germanium (20 $\left.\mu \mathrm{g} \mathrm{l}^{-1}\right)$ and was adjusted to $\mathrm{pH}=7.0$. The flow rate was $0.6 \mathrm{ml}$ $\mathrm{min}^{-1}$. Standards of sodium selenite, sodium selenate, selenocystine, selenomethionine and Se-methylselenocysteine (Merck, Germany) were used for the calibration and identification of selenium species. The identification of species was based on the retention time of the standards.

The chromatographic analysis of the selenium species is completed within $8 \mathrm{~min}$, because under these conditions the retention times of selenate $\left(\mathrm{Se}^{\mathrm{VI}}\right)$, selenite $\left(\mathrm{Se}^{\mathrm{IV}}\right)$, selenocystine ((SeCys) $\left.)_{2}\right)$, Se-methyl-selenocysteine (MeSeCys) and selenomethionine are $2.5 \pm 0.1 \mathrm{~min}$, $2.8 \pm 0.05 \mathrm{~min}, 3.3 \pm 0.15 \mathrm{~min}, 4.4 \pm 0.2$ and $7.3 \pm 0.3 \mathrm{~min}$, respectively. For the analysis of malt samples, however, it was necessary to prolong the analysis time to $32 \mathrm{~min}$ in order to achieve the elution of other species. The setting of ICP-MS instrument is summarised in Table 1.

ICP-MS is an element-specific method of detection and the areas of chromatographic peaks obtained in LCICP-MS analysis are proportional to the mass of the corresponding element contained in the eluted species. Therefore, any well-defined compound of the element can be used as a basis for calibration. To quantify selenium mass corresponding to individual peaks, we used a calibration curve obtained by the analysis of standard solutions (10, 20 and $40 \mathrm{mg} \mathrm{l}^{-1}$ of Se) prepared from sodium selenite. To perform these measurements, the analysis was shortened to 6 min (number of replicates was decreased to 300). The calibration was carried out before each series of samples and after four sample injections, the calibration was repeated. The quantification of selenium was based on the signal of selenium related to the signal of internal standard. This means that peak areas were calculated by numerical integration of the ratio of intensities ${ }^{80} \mathrm{Se} /{ }^{72} \mathrm{Ge}$ in the corresponding time interval. The quantities of individual selenium compounds corresponding to detected and identified organic selenium species were calculated by multiplying the found selenium mass or mass fraction by the stoichiometric factor $(2.116,2.306$ and 2.484 for (SeCys), MeSeCys and SeMet, respectively). 
Table 1 Setting of ICP-MS

\begin{tabular}{|c|c|c|}
\hline Parameter & Total Se determination & LC-ICP-MS analysis \\
\hline Measurement mode & DRC & DRC \\
\hline RF power (W) & 1100 & 1100 \\
\hline Gas flow rate $\left(1 \min ^{-1}\right)$ & 11.0 & 11.0 \\
\hline Auxiliary gas flow rate $\left(1 \mathrm{~min}^{-1}\right)$ & 1.0 & 1.0 \\
\hline Nebulizer gas flow rate $\left(I \mathrm{~min}^{-1}\right)$ & 0.68-0.77 (optimised) & 0.72 (optimised) \\
\hline DrRC gas and its flow (ml min$\left.{ }^{-1}\right)$ & $\mathrm{CH}_{4}, 0.5$ & $\mathrm{CH}_{4}, 0.2$ \\
\hline Operating mode of ionic lenses & Auto Lens on & Auto Lens on \\
\hline Chamber temperature $\left({ }^{\circ} \mathrm{C}\right)$ & 5 & 5 \\
\hline Signal measurement & Peak hopping & Peak hopping \\
\hline Isotopes measured & ${ }^{80} \mathrm{Se},{ }^{78} \mathrm{Se},{ }^{72} \mathrm{Ge},{ }^{74} \mathrm{Ge}$ & ${ }^{80} \mathrm{Se},{ }^{72} \mathrm{Ge},{ }^{74} \mathrm{Ge}$ \\
\hline Sweeps per replicate & 10 & 10 \\
\hline Dwell time per an isotope (ms) & 50 for Se, 20 for $\mathrm{Ge}$ & 68 for Se, 20 for Ge \\
\hline Number of replicates & 10 & 1600 \\
\hline Replicate time (s) & 1.4 & 1.2 \\
\hline Total measurement time & $14 \mathrm{~s}$ & $32 \min$ \\
\hline
\end{tabular}

\section{Results and discussion}

The subject of the analyses was the content of selenium and of its species in selenium-enriched green malt and kilned malt. A slight inhibition of germination was obvious in the case of sodium selenite application, probably because the dose of selenium was too high. The control sample germinated normally.

The total selenium contents expressed on fresh weight basis in the enriched malts were $40.3 \pm 1.5 \mu \mathrm{g}$ $\mathrm{g}^{-1}$ and $64.5 \pm 4.5 \mu \mathrm{g} \mathrm{g}^{-1}$ for green and kilned malt, respectively. The corresponding moisture contents, determined gravimetrically, were $40.9 \%$ and $3.5 \%$, respectively. In contrast, the total selenium contents in both control malt samples were $<0.02 \mu \mathrm{g} \mathrm{g}^{-1}$. Low selenium content in normal barley malt is given by soil conditions in the Czech Republic. In Spain, some attempts have been made to increase the selenium content in barley and consequently in malt and beer using additions of selenate or selenite into soil at the doses 10-20 g of Se per ha (Rodrigo et al., 2014).

The first step in selenium speciation analysis of selenium-enriched malts consisted in sample hydrolysis, which is a mandatory step for releasing the selenium species from the matrix. The enzyme hydrolysis using protease XIV was effective in solubilisation of the majority of selenium content from malt samples. The soluble portion of selenium corresponded to $75 \%$ and $95 \%$ of total selenium content in green and kilned malt, respectively, which is equivalent to the selenium mass fractions of $30.3 \mu \mathrm{g} \mathrm{g}^{-1}$ in the green malt and $61.3 \mu \mathrm{g} \mathrm{g}^{-1}$ in the kilned malt.
The reversed phase chromatography with mobile phase containing two ion pairing agents and methanol in a malonic buffer was used for the separation of selenium species. This method was described by Zheng (Zheng et al., 2000) and was recently slightly modified (Balán et al., 2014). It enables the determination of both inorganic and some organic selenium species, however, in the presence of selenite, the resolution between the peaks of selenate and selenite and the resolution between the peaks of selenite and selenocystine is not perfect. The elution profiles of soluble selenium species in green and kilned malts are analogous (see Figure 2), but the proportion of the two inorganic species ( $\mathrm{Se}^{\mathrm{VI}}$ and $\left.\mathrm{Se}^{\mathrm{IV}}\right)$ is different. In addition to selenate, selenite, selenocystine, Se-methyl-selenocysteine and selenomethionine, several unknown selenium species were detected including a highly retained one eluted at $30 \mathrm{~min}$. Therefore, the analysis had a longer duration.

The mass balance of selenium in the course of chromatography disclosed that the hydrolysed samples contain considerable amount of unknown selenium species that are not eluted at all under the chosen chromatographic conditions. This totally retained selenium represents $55 \%$ and $33 \%$ of the total soluble selenium in the green and the kilned malt, respectively. To elute the retained selenium compounds from the chromatographic column, it had to be rinsed with $50 \%$ methanol and $100 \%$ methanol after each series of malt sample analyses.

Figure 3 gives a detailed view of green malt sample analysis showing the selenium species eluted within the first 10 min of analysis. The summary of results is given in Table 2. It should be noted that the detected seleno- 
Figure 2 Chromatograms of selenium species in hydrolysed samples of selenium-enriched green malt and kilned malt

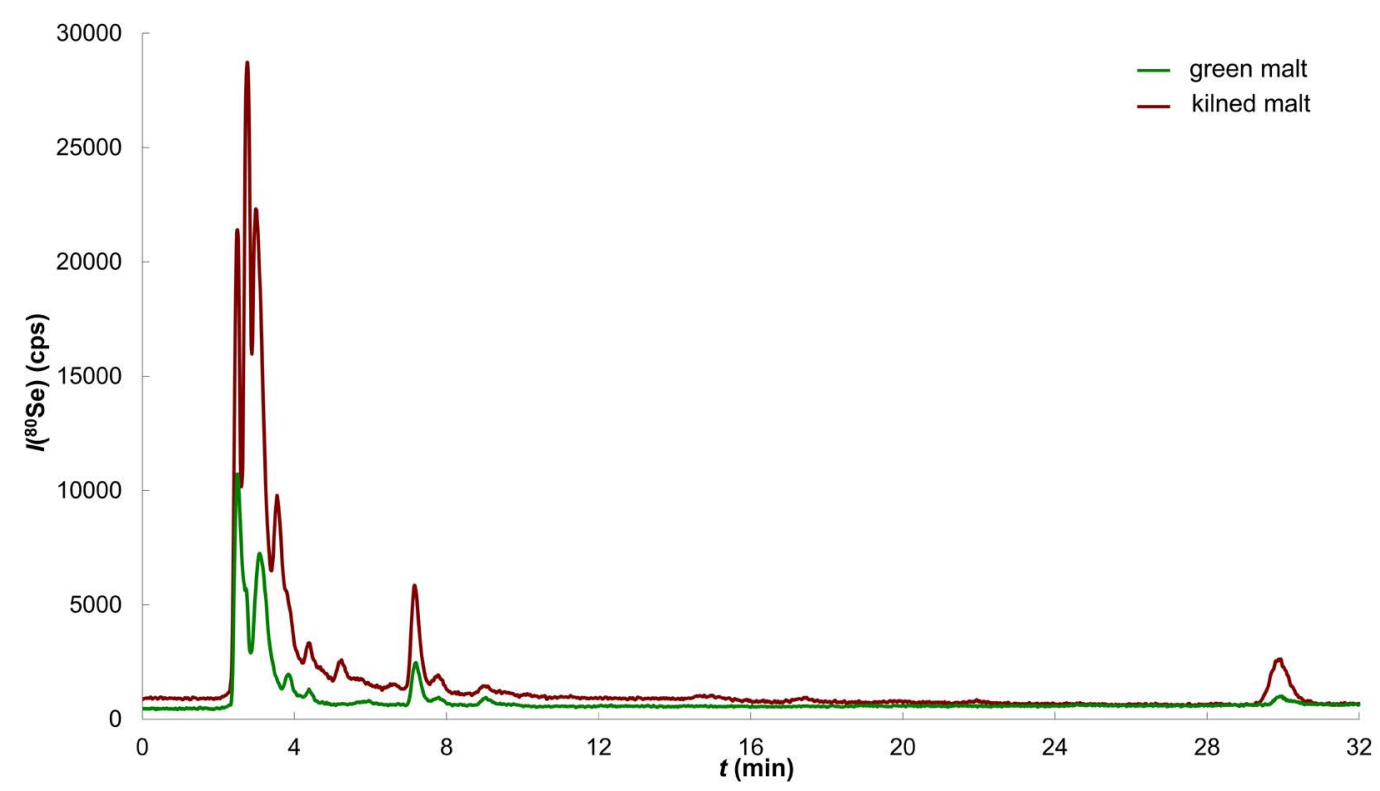

Figure 3 Chromatogram of main selenium species in the hydrolysed sample of green selenium-enriched malt (a detailed view)

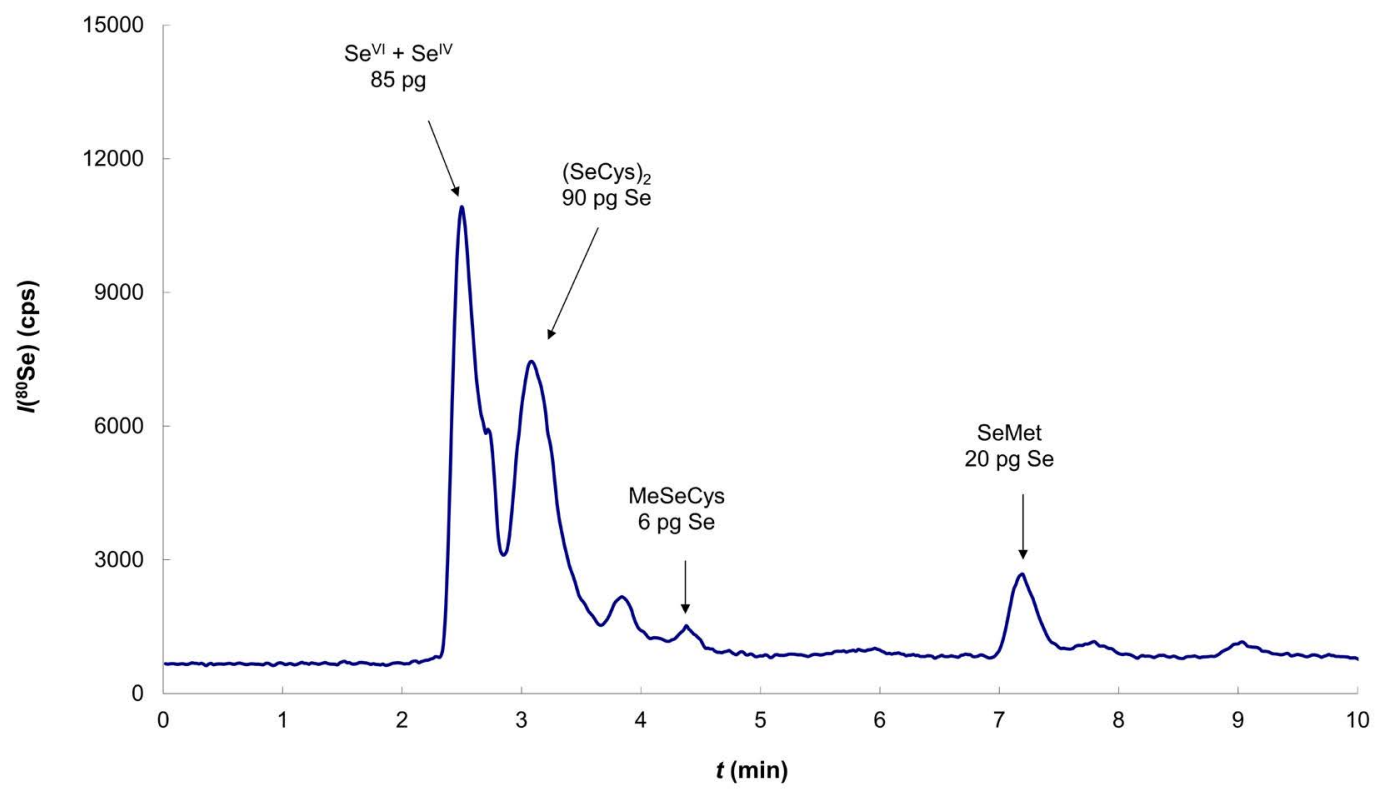

Table 2 Results of main selenium species determination in selenium-enriched kilned malt*

\begin{tabular}{|c|c|c|c|}
\hline Retention time of peak $(\mathrm{min})$ & Identity of species & Content of selenium $\left(\mu \mathrm{g} \mathrm{g}^{-1}\right)$ & Content of compound $\left(\mu \mathrm{g} \mathrm{g}{ }^{-1}\right)$ \\
\hline $2.50^{* *}$ & $\mathrm{Se}^{\mathrm{V}}+\mathrm{Se}^{\mathrm{IV}}$ & 4.90 & \\
\hline 3.08 & $(\mathrm{SeCys})_{2}$ & 5.20 & 11.0 \\
\hline 3.86 & unknown & 0.74 & 1.0 \\
\hline 4.38 & MeSeCys & 0.45 & 2.4 \\
\hline 7.20 & SeMet & 0.98 & \\
\hline 7.78 & unknown & 0.31 & \\
\hline 9.02 & unknown & 0.51 & \\
\hline
\end{tabular}

* The more retained compounds ( $t_{\mathrm{R}}$ from 10 to $30 \mathrm{~min}$ ) and totally retained compounds are not included. ** Including the shoulder at $2.8 \mathrm{~min}$. 
Figure 4 Chromatogram of main selenium species in the hydrolysed sample of kilned selenium-enriched malt

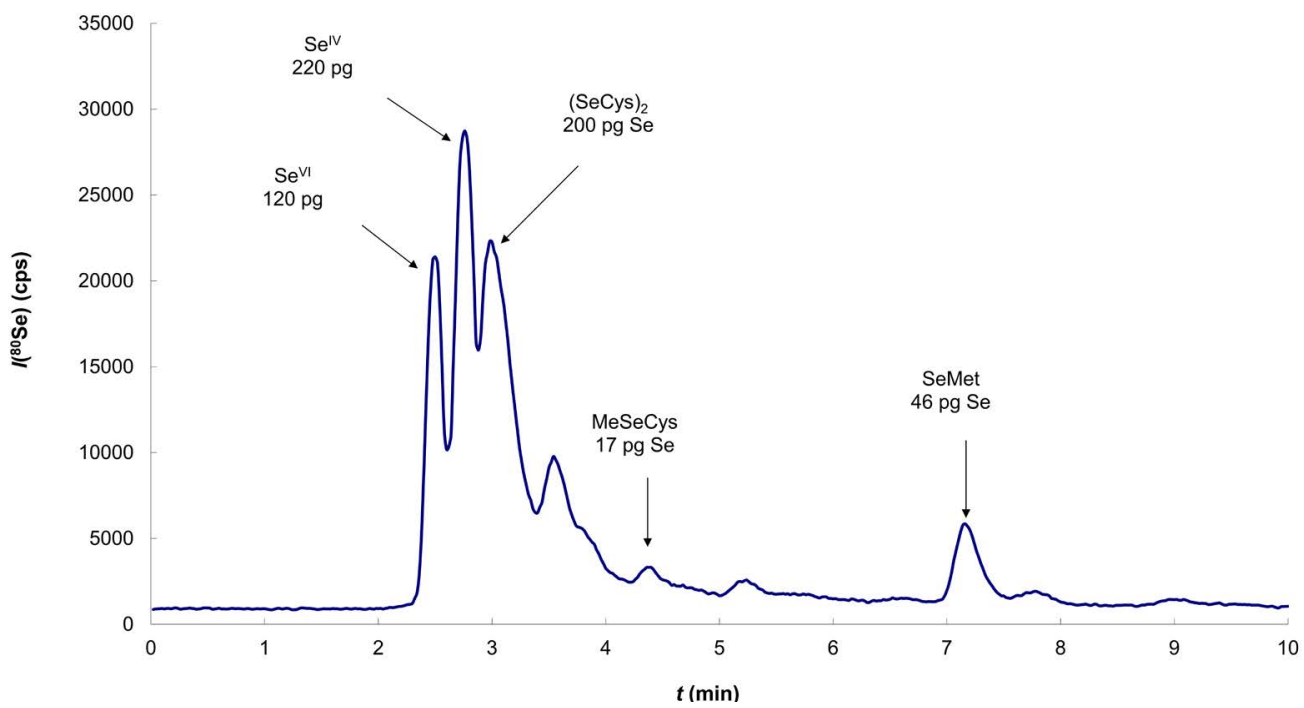

cystine (symbol (SeCys) ${ }_{2}$ ) actually represents selenocysteine, because selenocysteine liberated from selenopeptides and selenoproteins is oxidised during enzyme hydrolysis (Zheng, 2000) to the corresponding diselenide, i.e. to selenocystine.

The corresponding analysis of selenium species in kilned malt sample is shown in Figure 4 and the results are summarised in Table 3

Differences between the occurrence of selenium species in the green and kilned malt consist namely in the content of inorganic species. Selenium was added to steeped grain as selenite, but in the green malt selenate prevails over selenite, as a result of oxidation from tetravalent to hexavalent selenium state. On the contrary, in kilned malt both inorganic species are present in an approximately equal amount. This is probably caused by reducing power of reductones and other easily oxidisable compounds created in the course of kilning via Maillard reaction of carbohydrates (Velíšek, 2014).

The results proved that the biotransformation of inorganic selenium to organic selenium species really takes place during the malting process. Nevertheless, some selenium remains in the inorganic states. The selenium contained in the form of known organoselenium species (seleno amino acids) amounts to ca. $14 \mu \mathrm{g} \mathrm{g}-1$ of Se, which represents $22 \%$ of the total selenium in selenium-enriched kilned malt. On the other hand, the content of inorganic selenium species is ca. $14 \mu \mathrm{g}$ g- 1 of Se, which represents $25 \%$ of the total selenium. Rodrigo and her co-workers (Rodrigo et al., 2014) also found appreciable portions of selenite in malts made from Se-fertilised barley, but they determined selenomethionine as the main species. In our experiment the remaining part (34 $\mu \mathrm{g}$ g-1 of Se or $52 \%$ of the total Se) accounts for insoluble selenium compounds

Table 3 Results of main selenium species determination in selenium-enriched kilned malt*

\begin{tabular}{|c|c|c|c|}
\hline Retention time of peak (min) & Identity of species & Content of selenium ( $\mu \mathrm{g} g-1$ ) & Content of compound ( $\mu \mathrm{g} g-1$ ) \\
\hline 2.52 & $\mathrm{SeVI}$ & 6.16 & \\
\hline 2.76 & SelV & 11.1 & \\
\hline 3.05 & (SeCys)2 & 10.0 & 21.2 \\
\hline 3.56 & unknown & 5.46 & \\
\hline 4.36 & MeSeCys & 1.44 & 3.3 \\
\hline 5.22 & unknown & 1.25 & \\
\hline 7.20 & SeMet & 2.27 & 5.6 \\
\hline 7.78 & unknown & 0.41 & \\
\hline 9.02 & unknown & 0.63 & \\
\hline
\end{tabular}

* The more retained compounds (tR from 10 to $30 \mathrm{~min}$ ) and totally retained compounds are not included. 
and unknown organic selenium compounds including very hydrophobic species that were not eluted from chromatographic column. The strongly retained compounds are probably some organic selenides and diselenides created by various reactions from selenium containing amino acids; it is known that plant metabolism of selenium includes the formation of dimethyl selenide (DMSe) and dimethyl diselenide (DMDSe) (White, 2018). The enzymes converting selenomethionine or Se-methyl selenocysteine to DMSe or DMDSe were found in a number of plant species (Schiavon \& Pilon-Smits, 2017; White, 2018), so it is probable that these processes can take place also in barley. For the determination of organic selenides and diselenides, gas chromatography is a better choice.

As the transformation of inorganic selenium compounds into selenium containing amino acids was proved, the used approach could be utilised, after necessary modifications, for the production of beer with an increased content of selenium in highly bio-available chemical form. However, the dosing of selenite should be considerably lower. It should be noted, according to the results of the Spanish study (Rodrigo et al., 2014), that a high percentage of selenium loss is expected during the whole brewing process.

\section{Conclusion}

The experiments showed that a penetration of selenite into the grain can be achieved by spraying its solution onto steeped barley. A part of the selenite is transformed into organic selenium compounds. The analysis showed the presence of selenocystine (the product of selenocysteine oxidation), selenomethionine, and trace amounts of Se-methylselenocysteine. As a further recommendation for future tests, a reduced dose of selenium compound should be used when preparing the malt sample.

\section{References}

Balán, J., Vosmanská, M., Mestek, O., \& Száková, J. (2014). Speciační analýza selenu v odtučněném řepkovém šrotu. Chem. Listy, 108(3), 256-263

Bañuelos, GS., \& Mayland, HF. (2000). Absorption and distribution of selenium in animals consuming canola grown for selenium phytoremediation, Ecotoxicol. Environ. Saf., 46(3), 322-328. https://doi. org/10.1006/eesa.1999.1909

Bennett, DC., \& Cheng, KM. (2010). Selenium enrichment of table eggs. Poult. Sci., 89(10), 2166-72. https://doi.org/10.3382/ps.2009-00571

B'Hymer, C., \& Caruso, J. A. (2006). Selenium speciation analysis using inductively coupled plasma-mass spectrometry. J. Chromatogr. A, 1114(1), 1-20. https://doi.org/10.1016/j.chroma.2006.02.063

Brewers of Europe,[online]. Beer statistics 2018 edition, https:// brewersofeurope.org/uploads/mycms-files/documents/publications/2018/EU-beer-statistics-2018-web.pdf.[2019-03-30]
Broadley, M.R., Alcock, J., Alford, J. et al. (2010). Selenium biofortification of high-yielding winter wheat (Triticum aestivum L.) by liquid or granular Se fertilisation. Plant Soil 332: 5. https://doi.org/10.1007/ s11104-009-0234-4

Dauchy, X., Potin-Gautier , M., Astruc, A., \& Astruc, M. (1994). Analytical methods for the speciation of selenium compounds: a review. Fresenius J. Anal. Chem., 348(12), 792-805.

Dumont, E., Vanhaecke, F., \& Cornelis, R. (2006). Selenium speciation from food source to metabolites: a critical review. Anal. Bioanal. Chem., 385(7), 1304-1323. https://doi.org/10.1007/s00216-006-0529-8

Eurola, M., Ekholm, P., Ylinen, M., Koivistoinen, P., \& Varo, P. (1989). Effects of selenium fertilization on the selenium content of selected Finnish fruits and vegetables. Acta Agr. Scand, 39(3), 345-350. https://doi. org/10.1080/00015128909438526

European Food Safety Authority (EFSA), (2014). Scientific Opinion on Dietary Reference Values for selenium. EFSA Journal, 12, 3846-3913. https://doi.org/10.2903/j.efsa.2014.3846

Irons, R., Carlson, BA., Hatfield, DL., Davis CD. (2006). Both selenoproteins and low molecular weight selenocompounds reduce colon cancer risk in mice with genetically impaired selenoprotein expression. J. Nutr., 136(5), 1311-1317. https://doi.org/10.1093/jn/136.5.1311

Kvíčala, J., Zamrazil V., Němeček, J., \& Jiránek, J. (2008). Selenium status of South Bohemia seniors characterized by INAA of blood serum. J. Radioanal. Nucl. Chem., 278(3), 537-541. https://doi.org/10.1007/s10967-008-1001-3

Li, G., Wang, F., Kang, D., \& Li, C. (1985). Keshan disease: An endemic cardiomyopathy in China. Hum. Pathol., 16(6), 602-609.

Ludvíková, E., Pavlata, L., Vyskočil, M., \& Jahn, P. (2005). Selenium Status of Horses in the Czech Republic. Acta Vet. Brno, 74(3), 369-375, https://doi.org/10.2754/avb200574030369

Navarro-Alarcon, M., \& Cabrera-Vique, C. (2008). Selenium in food and the human body: a review. Sci. Total Environ., 400(1-3), 115-141. https://doi.org/10.1016/j.scitotenv.2008.06.024

Muñoz Olivas, R., Donard, O.F.X., Cámara, C., \& Quevauviller P. (1994). Analytical techniques applied to the speciation of selenium in environmental matrices. Anal. Chim. Acta, 286(3), 357-370. https://doi. org/10.1016/0003-2670(94)85082-8

Pedrero, Z, \& Madrid, Y. (2009). Novel approaches for selenium speciation in foodstuffs and biological specimens: A review. Anal. Chim. Acta, 634(2), 135-152. https://doi.org/10.1016/j.aca.2008.12.026

Pyrzyńska, K. (1996). Speciation analysis of some organic selenium compounds: A review. Analyst, 121, 77R-83R. https://doi.org/10.1039/ AN996210077R

Pyrzyńska, K. (2009). Selenium speciation in enriched vegetables. Food Chem., 114(4), 1183-1191. https://doi.org/10.1016/j.foodchem.2008.11.026

Rodrigo S., Santamaria O., Chen Y., McGrath S.P., \& Poblaciones M.J. (2014). Selenium speciation in malt, wort, and beer made from selenium-biofortified two-rowed barley grain. J. Agric. Food Chem. 62 (25), 5948-5953. https://doi.org/10.1021/jf500793t

Roman, M., Jitaru, P. \& Barbante, C.,( 2013). Selenium biochemistry and its role for human health. Metallomics. 6(1), 25-54. https://doi. org/10.1039/c3mt00185g

Scientific Committee on Food: Opinion of the Scientific Committee on Food on the Tolerable Upper Intake Level of Selenium http://www. europa.eu.int/comm/food/fs/sc/scf/index_en.html. [2000-10-19]

Střítecká, H., Hlubik, P., \& Nováková, J. (2009). Serum selenium status in a group of 386 volunteers from the Czech Republic Rescue Fire Brigades. Mediterr. J. Nutr. Metab., 2(2), 133-138. https://doi. org/10.1007/s12349-009-0049-0

Schiavon, M., \& Pilon-Smits E.A.H (2017). The fascinating facets of plant selenium accumulation - biochemistry, physiology, evolution and ecology. New Phytol., 213(4), 1582-1596. https://doi.org/10.1111/nph.14378 
Szpunar, J. (2000). Bio-inorganic speciation analysis by hyphenated techniques. Analyst, 125(5), 963-988. https://doi.org/10.1039/A909137H

Templeton, D.M., Ariese, F., Cornelis, R., Danielsson, L.G., Muntau, H., van Leeuwen, H.P., \& Łobiński, R. (2000). Guidelines for terms related to chemical speciation and fractionation of elements. Definitions, structural aspects, and methodological approaches (IUPAC recommendations 2000). Pure Appl. Chem., 72(8), 1453-1470.

Uden, P.C. (2002). Modern trends in the speciation of selenium by hyphenated techniques. Anal. Bioanal. Chem., 373(6), 422-431. https://doi. org/10.1007/s00216-002-1405-9
Velíšek, J., 2014: The Chemistry of Food, Wiley-Blackwell. ISBN 9781118383810.

White P.J. (2018). Selenium metabolism in plants. Biochem. Biophys. Acta Gen. Subj., 1862, 2333-2342. https://doi.org/10.1016/j.bbagen.2018.05.006

Zheng, J., Ohata, M., Futura, N., \& Kosmus, W. (2000). Speciation of selenium compounds with ion-pair reversed-phase liquid chromatography using inductively coupled plasma mass spectrometry as element-specific detection. J. Chromatogr. A, 874(1), 55-64. 